\title{
A Review on Studies of Library Efficiency Evaluation by Using DEA Method
}

\author{
Li-zhong TIAN ${ }^{1}$ and Ai-chen ZHANG ${ }^{2}$ \\ ${ }^{1}$ Library of Tianjin University of Technology, Tianjin, 300384, China \\ ${ }^{2}$ Tianjin University of Technology, Tianjin, 300384, China
}

Keywords: Library efficiency, Input / output efficiency, Data envelopment analysis(DEA).

\begin{abstract}
Chinese public cultural undertakings are increasingly developing and the input level is gradually improving. In such context, more and more studies began to focus on how to evaluate public cultural service organizations such as public library. The aim of this paper is to analysis papers on library efficiency in library and information science since 1982. The concept of library input-output efficiency is extracted from the overall framework of library performance. Library efficiency is different from the high level concept of "library performance" and the same level concept of "library effectiveness" respectively. Furthermore, this paper discusses the characteristics of library efficiency evaluation, efficiency measurement of DEA, criteria for selecting efficiency indicators and influencing factors.
\end{abstract}

\section{Introduction}

Under the policy of promoting the construction of public cultural undertakings, government departments began to increase investment and support for libraries and other cultural service institutions while emphasizing the establishment public cultural service system and improving the capacity of public cultural services. China's "13th Five-Year plan" proposed that we should promote the standardization and equalization of basic public cultural services, and enhance the capacity building of grass roots cultural services. The public library thus has obtained more funds, resources and policy support than ever before. The development of library cause is being in a positive and development space.

Under the above policy background, the government and the public began to pay attention to the management and development of the public library. As we all know, the operation of public library is mainly dependent on public funds, but public funds belong to the scarce resources of society. The public library, in order to get more financial support, must prove that the library can provide the best services with the least funds, or have made the most effective allocation of public resources without waste or inefficient problems.

Public library is a non-profit nature. It can't calculate the ratio of input to output as well as other profitable organizations. How can we prove that government's investment in public libraries is valuable? How can we have more advantages in the competition with other sectors' funds and resources? A comprehensive survey of research results at home and abroad shows that the existing research on library efficiency measurement mainly adopts data envelopment analysis (DEA) ${ }^{[1]}$. Data envelopment analysis (DEA) reveals whether libraries use public resources to provide users with proper services and generate sufficient benefits.

On the basis of summarizing the existing literature, this study makes a systematic review, mainly answering the following questions. (1) How to explain the concept of library efficiency from the perspective of Library and Information Science? (2) How to accurately measure the efficiency of library using an economic concept? Is there a problem? (3)Which factors have an impact on the efficiency of the library? 


\section{Interpretation of the Concept of Library Efficiency}

Library efficiency means the ability of a library to transform its inputs (resources) into outputs (products or services). It refers to the input-output efficiency of the library. As a public cultural service institution, efficiency means how much products and services can be provided on the basis of existing resources. Or how much resources should be invested to meet the required product and service volume. So, we can make such a hypothesis: If the manager of the library has achieved the goal of maximizing service products at a given level of resource input, thus the library is efficient.

In 1980s some foreign scholars began to consider the library's funds, manpower and literature resources as input capital, and used this to evaluate library efficiency[2]. Hayes used the economic mathematics model to calculate the labor and capital input of the library to explain the products of the library ${ }^{[3]}$. Naylor made a comparative study of the three aspects of book funding, collection size and library service numbers to measure the efficiency of libraries ${ }^{[4]}$.

Data envelopment analysis (DEA) has gradually become the mainstream method of library efficiency evaluation in $1990 \mathrm{~s}^{[5][6]}$. Its core principle is to use mathematical programming model to evaluate the relative validity of multiple inputs, multiple output departments or units ${ }^{[7]}$. Easun used DEA to measure the efficiency of university libraries transforming resources into library or school related outputs ${ }^{[8]}$.Some person such as Bai shouyan, Wu yuhua, Wang hui, Li jianxia, etc. used this method to measure the efficiency of university and provincial public libraries respectively.

What needs to be pointed out is that there are two modes of library performance --library efficiency and library effectiveness. Library efficiency reflects the ability of libraries to convert various input resources into multiple outputs (services), with the emphasis on how much the library resources are used by the users. Library effectiveness is concerned about the impact of library services on users ${ }^{[9]}$. A successful library needs both effectiveness and efficiency of the two parties. only in the case of efficiency and effectiveness at the best time, the library can improve the performance level and ensure the organizational goals of the library ${ }^{[10]}$.

To sum up, we know that the calculation of the input-output efficiency of the library is in fact a study of whether the allocation of the resources of the library is reasonable or not, whether the construction scale is compatible with the speed of development from the angle of economics. The calculation of library input and output efficiency deepens and enriches the cognition and evaluation of library operation, providing a deep theoretical explanation for library management and development.

\section{Measurement Methods and Problems}

The calculation of library efficiency is originally derived from the field of economics. The researchers mainly use the DEA method to calculate and compare the efficiency of the non-profit organizations such as the library ${ }^{[11]}$. Later library and information science also began to pay attention to library efficiency. Relevant studies have confirmed that DEA is the core tool of library efficiency evaluation. DEA efficiency results can provide very accurate input / output index data for low efficiency libraries for their improvement ${ }^{[12]}$, and library managers can choose new strategies to improve the operating efficiency of the library ${ }^{[13]}$.

(1) The measurement of library efficiency is comprehensive, mainly based on technical efficiency, scale efficiency and pure technical efficiency. A few studies have increased the efficiency measure of redundancy, congestion and super efficiency in library. But the overall measurement efficiency of library efficiency is not ideal enough to get the development trend of library efficiency change. Most researchers only measure the efficiency of a year for the difficulty in obtaining statistical data. If we can get years of data, we can more perfect and effectively use the DEA method to measure the development and trend prediction of the library.

(2)The sample type is mainly composed of two main types: university libraries and public libraries, and lacks the efficiency of other types of libraries. In addition to university libraries and public libraries, other types of libraries are seldom concerned and studied. Because of the lack of a 
continuous and comparable statistical information database, it is very difficult for researchers to collect data, so it is impossible to estimate their efficiency.

In addition, there is a special form of provincial and city libraries in China ${ }^{[14]}$. In fact, provincial and city libraries do not take the individual of the library as the research object, but take the administrative region as the research object. The average level of statistical indicators of the library in the region represents the overall level of the regional library's input or output. The main reason for this special phenomenon is that the statistical data of the single library are often difficult to collect, and the quantitative data in the provinces and cities are easier to obtain.

(3)The sample size of library efficiency evaluation is generally small, and the sample size is mostly between $1 \sim 50$. The DEA method has a clear requirement for the quantity of sample and the number of input / output indicators. That is, the number of libraries involved in the efficiency measurement must be at least three times the sum of the number of inputs and outputs ${ }^{[15]}$, so that the statistical error can be avoided. Therefore, insufficient sample size will limit the number of input and output indicators, and further affect the accuracy of statistical results.

(4)Previous studies have found that the efficiency of the investigated library is generally low. In the study of efficiency evaluation of 184 public libraries in New York, Vitaliano found that the most efficient library accounted for only $12.5 \%$ of the total sample size ${ }^{[16]}$. Sharma evaluated the efficiency of 47 public libraries in Hawaii, and found that $29 \%$ of library efficiency is the best ${ }^{[17]}$. In the research of Worthington, Hammond and Reichmann, the proportion of efficiency is $10.1 \%, 34.6 \%$ and $28.8 \%$ respectively, not more than half ${ }^{[18]}[19]$. To sum up, there are some drawbacks in the utilization of library resources, and the overall efficiency level needs to be improved.

\section{Selection Characteristics of Efficiency Index}

Which indicators to measure library efficiency is crucial to the overall research, which is determined by the characteristics of the DEA method. The DEA efficiency score is a relative value. It is calculated in a certain library sample and selected specific input and output indicators. At the same time, these indicators must fully reflect the status of the service output of the library. Therefore, once the sample size of library is increased or the input output index changes, the efficiency score of library will change immediately. Specifically, previous studies have shown the following characteristics in the selection of efficiency indicators:

Table1. The main indexes of library efficiency measurement and use

\begin{tabular}{|c|c|c|}
\hline \multirow[t]{2}{*}{$\begin{array}{l}\text { Input } \\
\text { index }\end{array}$} & $\begin{array}{c}\text { contro-llable } \\
\text { index }\end{array}$ & $\begin{array}{l}\text { funding resources: total expenses, operating expenses, wage funds, paper books funds, and } \\
\text { electronic resources funds } \\
\text { collection resources: total collection, library collection, periodical collection, new } \\
\text { collection, paper collection, electronic collection (the quantity of } \\
\text { electronic periodicals, electronic books, the quantity of WEB } \\
\text { database, the number of independent development database) } \\
\text { the number of logistics staff, the number of work study staff) } \\
\text { human resources: the number of employees (specifically the number of professional staff, } \\
\text { the area of a library, the number of seats, and the electronic } \\
\text { facilities( such as the number of computers) } \\
\text { service time: the number of days to open every year, the time for the opening of the } \\
\text { library every week }\end{array}$ \\
\hline & $\begin{array}{l}\text { Uncont-rollabl } \\
\text { index }\end{array}$ & $\begin{array}{l}\text { resident population: resident population (non Chinese population, elderly population, } \\
\text { student population), non resident population and population } \\
\text { density in service area }\end{array}$ \\
\hline \multicolumn{2}{|c|}{ Output index } & $\begin{array}{l}\text { resource utilization: circulation rate, interlibrary loan volume, library visits, lending } \\
\text { volume, database usage, reference volume, online consultation } \\
\text { volume and document delivery volume } \\
\text { user: the number of users, user satisfaction, number of academic papers published, } \\
\text { students' standardized test scores, library education and resource utilization } \\
\text { education }\end{array}$ \\
\hline
\end{tabular}




\section{Analysis of Selection Characteristics of Input Index}

As shown in Table 1, this paper classifies the efficiency indicators in previous studies and finds that the input and output status of the majority of the research are supported by multiple indicators. Among them, the input indicators of efficiency can be divided into two categories: controllable indicators and uncontrollable indicators according to whether they can be controlled by libraries ${ }^{\text {[20] }}$

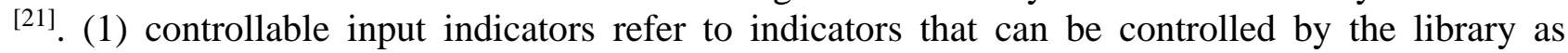
"standard" or "freely determined". Human resources, funds, collection resources, hardware facilities and library service time are five common controllable input indicators in libraries.

The three indicators of library human resources, collection resources, funds and service time are more persuasive to describe the core input of the library, which is also the input index of the researchers with high frequency. In addition, some studies suggest that specific indicators such as the size of the library, opening hours and funds can also be used to measure the library's input ${ }^{[22] ~[23] . ~}$

However, individual indicators are still controversial in their categories such as the service time of the library. In the study of Chen and Reichmann ${ }^{[24]}$, the service hours of libraries are classified as output indicators. Other scholars such as Hammond ${ }^{[25]}$ and Sharma regard service hours as input indicators. Taking the service hours of libraries into the category of Library output indicators, this paper thinks that such research design is to be debatable.

(2) Uncontrollable input index is relative to the controllable index. It refers to those resources that are beyond the freedom of the library manager to control. These indicators mainly include population density, area, population and socioeconomic index in the library area.

In the process of selecting the above uncontrollable indicators, there are still some problems that need special focus. When DEA is used to measure libraries in the same area, there is no obvious difference in the social environment factors such as population density, area size, resident population and so on, which will not affect the reliability of the efficiency measurement. When decision making units come from different areas, this kind of uncontrollable input indicators will affect the efficiency of libraries.

Some studies think that some user characteristics of library can be regarded as input elements of library, just like all kinds of library resources. But the definition of user index is relatively vague. In the past studies, the user index was regarded as an output index or an incontrollable input index. As the output index, the number of users can be interpreted as the size of the user community developed by the library. As an index of uncontrollable input, the number of users can be regarded as the output of library literature resources and consulting services. The number of users is affected by the size of their users. The larger the user scale, the higher the number of services and resource utilization, and vice versa.

(3) The index of human resources is in the controllable and uncontrollable index system at the same time, and the attribution of human condition has not yet been reached.

\section{Analysis of the Selection Characteristics of Output Indicators}

Output indicators can be roughly divided into two categories: resource utilization and user feedback.

(1) Resource utilization, the commonly used output indexes include circulation rate, interlibrary loan amount, user access, book loan amount, reference quantity, online consultation and document delivery, etc.

Foreign scholars prefer to use circulation rate and reference volume as output indicators. In the study of Chen[30], Hammond[26] and Sharma[24], it is agreed that the circulation rate and the reference quantity are the main output indicators to measure the efficiency. It is more convincing to use these two indicators to measure the output of the library. Domestic scholars mainly use book lending volume and related indicators (such as per capita loan volume, interlibrary loan volume, etc.) as the core output of resource utilization.

(2) User feedback, user scale, user satisfaction, library use effect (such as the results of teacher's paper, student exam results, etc.), and the related education provided by the library are considered as an effective index to measure the output capacity of the library. 
The number of users is more use of output indicators. Teachers' scientific research output and students' academic achievement are common output indicators of university libraries and primary and middle school libraries. In order to measure the efficiency of the library, a questionnaire survey is needed to measure the satisfaction level of the user to the library and to form quantifiable data.

In a word, researchers choose indicators based on previous experience, author's personal preference and research focus in the process of index selection. Unfortunately, the tendency of the researchers is not emphasized in the results. The selection of input / output indicators determines the ranking of library efficiency to a large extent. However, the subjectivity of the index selection has been a major obstacle to efficiency evaluation for a long time. From the perspective of Economics, the main input and core service should be guided by the key input of the library in the selection of efficiency indicators. In this way, the true efficiency level of the library is reflected to the maximum extent.

\section{Influencing Factors and Operating Mechanism}

Because there are few studies on the causal variables of library efficiency, this has increased the difficulty in studying the mechanism of library efficiency. In the study of the relationship between library efficiency and other related factors, some literatures have found that the level of human resources in libraries will have an impact on library efficiency. Sharma and Miidla think that the cost of library human resources and its input has a significant effect on library efficiency.

Secondly, the allocation of resources to libraries will also remarkable affect the efficiency of libraries. Vitaliano's research proves that the long opening hours of libraries will adversely affect the overall efficiency ${ }^{[19]}$. Hammond found that excessive subscription of periodicals will also lead to the emergence of Library inefficiency ${ }^{[26]}$. In its 2011 assessment of the efficiency of university libraries, Younghee found that the inclusion of electronic resources in the assessment would also affect the efficiency of the university library to a great extent ${ }^{[27]}$. Hemmeter found in its research that competition among other private institutions can not improve the efficiency of libraries. However, local government's supervision and management of libraries can effectively enhance the efficiency of libraries ${ }^{[27]}$.

There are few researches on Library influencing factors in China. Only Guo Jun hua, Zhao Yanfang, Wang Wei etc. have done some research on the factors affecting library efficiency. Guo Junhua's research on the efficiency evaluation of 31 provincial libraries in China found that: (1) The annual per capita education of the local population has positive impact on the efficiency of the public library, that is, the more developed the local education is, the higher the efficiency of the public library is. (2) The GDP per capita is negatively correlated with the efficiency of public libraries, that is, the efficiency of Libraries in the economically developed areas is relatively low.(3) Financial allocation is positively related to library efficiency, but the impact is not obvious.

In the study of the efficiency of the public library in Shanghai, Zhao Yanfang found that the government's financial allocation to the library has a significant positive correlation with the efficiency level of the local public library. The population density of the library service area also has a significant positive correlation with the library efficiency, that is, the greater the population density, the higher the efficiency of the public library in this area. Wei Quanling found that the research on efficiency evaluation of Tokyo Library in Japan is consistent with Zhao Yanfang's research. That is, the efficiency of residential area library with larger population density is obviously higher than that of commercial district library with smaller population density. In addition, the 4 contents of the collection resources, the quality of the employees, the number of readers' activities and the economic value added in the region are also included in the study of the influence factors of the library. In fact, these 4 factors did not significantly affect library efficiency in the study.

The analysis of the influence of some uncontrollable indicators on library efficiency shows that the size of the library and the language of its users do not affect their efficiency. The population characteristics of the library service area affect the efficiency of the library to a certain extent. For example, if the library area has obvious business district characteristics, it will lead to a decline in 
library efficiency. If the library area has strong residential characteristics, it will enhance the efficiency of the local library.

\section{Conclusion and Prospect}

Through combing the research results of library efficiency at home and abroad, we can see that the research of foreign scholars started earlier, and the research process is longer and systematic. Library and information science, based on the pilot study of economics, has a certain reference value for the research of library input output efficiency in China. In recent years, the research on library efficiency has been increased by domestic scholars. On the whole, it is in an attempt stage. Further demonstration is needed on how to choose suitable models for computing and setting index weights. Looking at the research of library efficiency at home and abroad, I find that the following research should be paid attention to in the following aspects:

(1) The applicability of various measurement methods for library efficiency evaluation needs further demonstration. In addition to the DEA method, the calculation methods from different fields, such as the efficiency index comparison method, the nuclear principal component analysis, the orderly information aggregation, are used to calculate the efficiency. Whether these methods are applicable to libraries, the convenience of calculation process or application, and whether they can be popularized should be further explored and verified.

(2) The choice of indicators needs to be cautious. The researchers can freely choose the input output index according to the actual situation of the local area or library. The selection of the index largely determines the efficiency level. Therefore, we should be very careful in the selection of criteria, quantity and so on.

(3) The related research on the influencing factors of library efficiency level needs to be enriched. The existing research focuses on the efficiency of Library groups under different situations, and discusses more about improving the micro management of library management. There is a lack of in-depth analysis of the specific mechanisms that affect different factors on library efficiency, which should be emphasized in future research.

\section{Acknowledgement}

This article is one of the achievements of Tianjin's cultural and artistic planning subject, "Research on performance evaluation and optimization mechanism of Public Libraries" (project number: B14038).

\section{References}

[1] Chen T. An evaluation of the relative performance of university libraries in Taipei[J]. OCLC Systems \& Services, 1997, 13(4): 164-172.

[2] Zweizig D, Rodger E J. Output measures for public libraries: A manual of standardized procedures[M]. Chicago: American Library Association,1987.

[3] Hayes R M. An application of the Cobb-Douglas model to the association of research libraries[J]. Library and Information Science Research, An International Journal, 1983,5(3):291-325.

[4] Naylor R J. The Efficient Mid-Size Library: Comparing Book Budget to Population to Collection Size.[J]. Library Journal, 1987, 112(3):119-120.

[5] Abels E G, Kantor P B, Saracevic T. Studying the cost and value of library and information services: Applying functional cost analysis to the library in transition[J]. Journal of the American Society for Information Science, 1996,47(3):217-227. 
[6] Kao C, Lin Y C. Evaluation of the university libraries in Taiwan: Total measure versus ratio measure[J].The Journal of the Operational Research Society, 2004(12): 1256-1265.

[7] Charnes A, Cooper W W, Rhodes E. Measuring the efficiency of decision making units[J]. European Journal of Operational Research, 1978,2(6):429-444.

[8] Easun M S. Identifying efficiencies in resource management: An application of data envelopment analysis to selected school libraries in California[M]. UMI Dissertation Services,1994:2-3.

[9] Brophy P. Measuring library performance: Principles and techniques[M].London: Facet, 2006:7,8,106.

[10] Shim W. Applying DEA technique to library evaluation in academic research libraries[J].

Library Trends, 2003,51(3):312-332.

[11]Miidla P, Kikas K.The efficiency of Estonian central public libraries[J].Performance Measurement and Metrics, 2009,10(1):49-58.

[12]Kyrillidou M. An overview of performance measures in higher education and libraries[J]. Journal of Library Administration, 2002, 35(4): 7-18.

[13]Vitaliano D F. X-Inefficiency in the public sector: The case of libraries[J]. Public Finance Review, 1997,25(6):629-643.

[14]Wu Yuhua, Yang Shunyuan. Research on the efficiency measure of university library [J]. Information Magazine, 2007(9):129-131.

[15]Fu Caiwu, Zhang Weifeng. Research on efficiency, scale income and crowding phenomenon of provincial public libraries in China [J]. Chinese Soft Science,2017(10):72-81.

[16] Vitaliano D. Assessing public library efficiency using data envelopment analysis[J]. Annuals of public and cooperative economics, 1998,69(1):107-122.

[17] Sharma K R, Leung P, Zane L. Performance measurement of Hawaii State public libraries: an application of data envelopment analysis(DEA) [J]. Agriculture and Resource Economics Review, 1999,28(2):190-198.

[18]Worthington A. Performance indicators and efficiency measurement in public libraries[J]. Australian Economic Review, 1999,32(1):31-42.

[19] Hammond C J. Efficiency in the provision of public services: a data envelopment analysis of UK public library systems [J]. Applied Economics, 2002,34(5):649-657.

[20]Reichmann G, Sommersguter-Reichmann M. Efficiency measures and productivity indexes in the context of university library bench marking[J]. Applied Economics, 2010,42(3):311-323.

[21] Shim W, Kantor P B. Evaluation of digital libraries: A DEA approach[C]//Proceedings of the Annual Meeting-American Society for Information Science. Information Today; 1998, 1999, 36: 605-615.

[22]Hammond C J. The effect of organizational change on UK public library efficiency[J]. International Journal of Production Economics, 2009,121(1):286-295.

[23] Shim W. Assessing technical efficiency of research libraries[J]. Advances in Library Administration and Organization, 2000,17:243-339.

[24]Easun S. Beginners guide efficiency measurement: an application of data envelopment analysis to selected school libraries in California[J]. School Library Media Quarterly, 1994,22(2):103-106. 
[25]Chen T. An evaluation of the relative performance of university libraries in Taipei[J]. OCLC Systems \& Services, 1997, 13(4): 164-172.

[26] Noh Y. Evaluation of the resource utilization efficiency of university libraries using DEA techniques and a proposal of alternative evaluation variables[J]. Library Hi Tech, 2011, 29(4): 697-724.

[27] Hemmeter J A. Estimating public library efficiency using stochastic frontiers[J]. Public Finance Review, 2006,34(3): 328-348. 